\title{
EL JARDÍN Y OTROS ESPACIOS VITALES EN LA OBRA DE ToMÁs GonzÁlez*
}

\section{The Garden and Other Living Spaces in THE Work of Tomás González}

Néstor Salamanca León ${ }^{1}$

\footnotetext{
* Texto leído en el xxi Congreso de la Asociación de Colombianistas celebrado en la Universidad de los Andes en Bogotá entre el 15 y el 17 de julio del 2019.

Cómo citar esta conferencia: Salamanca León, N. (2020). El jardín y otros espacios vitales en la obre de Tomás González. Estudios de Literatura Colombiana 46, pp. 233-242. DOI: https://doi.org/10.17533/udea.elc. $\underline{\mathrm{n} 46 \mathrm{a} 12}$
}

Editores: Andrés Vergara Aguirre, Christian Benavides Martínes, Vanessa Zuleta Quintero

${ }^{1}$ https://orcid.org/0000-0002-4655-6114 musgo@orange.fr Université de Corse, Francia

Recibido: 11.08 .2019

Aprobado: 21.11.2019

Publicado: 27.12.2019

Copyright: este es un artículo de acceso abierto distribuido bajo los términos de la Licencia Creative Commons Atribución - No comercial - Compartir igual 4.0 Internacional

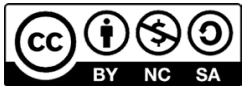

Tuve la suerte de conocer a Tomás González en Francia, este país de letras celebra cada año la literatura de un país extranjero en un evento llamado “Les belles étrangères” y en 2010 el país invitado fue Colombia. Lo acompañé durante tres días por la isla de Córcega que los griegos llamaron Kallisté: la isla de la belleza. Estos paisajes de playas idílicas y montañas escarpadas, que el novelista antioqueño visitaba por la primera vez, le fascinaron. Al leerlo luego más en detalle, comprendí mejor la razón: los paisajes naturales constituyen una preocupación constante en sus novelas, todas ellas se construyen a partir de geografías y territorios que evolucionan como verdaderos personajes. En su última novela, Las noches todas, publicada en 2018, esta inquietud espacial se acentúa.

En algunos artículos que he publicado sobre su obra, he tratado de explicar cómo sus ficciones se inician generalmente con un desplazamiento voluntario o forzado, o el recuerdo de un periplo pasado. En ellos analizo cómo el viaje constituye el elemento desencadenante del relato y cómo 
los paisajes descritos participan en la dirección de la historia. Hoy les propongo reflexionar sobre el espacio vegetal y, en particular, sobre los jardines en la narrativa de Tomás González, especialmente en su última novela.

La escritura de González ha evolucionado considerablemente desde su primera obra Primero estaba el mar de 1983. El narrador extradiegético ha ido cediendo terreno a un narrador en primera persona que toma cada vez más los rasgos de un narrador autoficcional. El novelista suele ocultar su identidad detrás de diferentes personajes que comparten aspectos de su propia vida, se trata siempre de artistas o intelectuales taciturnos y contemplativos como él. El título Las noches todas retoma la frase que cierra la novela, en ella se narra la vida, por no decir el fin de vida, de un profesor universitario recién jubilado que decide vender su apartamento en la capital para instalarse en una casa amplia de cierta ciudad colonial sobre el río Magdalena de donde es oriunda su familia materna.

A pesar de que la geografía ha ocupado siempre un lugar central en sus relatos, González vuelve a situar la acción en un pueblo que se resiste a nombrar y que el lector debe descubrir a partir de ciertas pistas que el narrador le ofrece. La inicial del caserío a donde llegan los protagonistas de su primera novela desaparece aquí para obviar llanamente el topónimo. Uniendo cabos, el lector intuye que dicha ciudad puede ser Puerto Salgar, en el departamento de Cundinamarca, donde el protagonista termina comprando una propiedad de dos mil metros de extensión. La intriga alrededor del lugar exacto de la acción despierta en el lector su interés por el espacio y sus características particulares. Al querer descubrir en dónde ocurren los hechos, los detalles sobre la geografía se leen con mayor atención.

El jardín ha sido desde la antigüedad un espacio de contemplación e interioridad. La voluntad de aclimatar especies vegetales ha interesado a muchos pueblos y culturas, desde los sumerios y romanos, pasando por los árabes que tras su paso por España dejan en la península su gusto por los jardines interiores, de ahí que el patio de la casa colonial americana sea legítimo heredero de esta estética paisajista oriental. Desde la antigüedad, el jardín ha sido siempre un espacio positivo, por eso aparece en diferentes cosmogonías como un territorio idealizado y edénico, un lugar desprovisto de peligros. Según la filosofía taoísta que practica Tomás González, el jardín es un espacio de equilibrio cósmico entre lo vacío y lo cultivado, es decir entre el yin y el 
yang (Cazenave, 2000, p. 330). La relación de los pueblos con el entorno que los acoge dice mucho sobre su idiosincrasia. El jardín, la finca y en general los espacios naturales en la obra de González expresan la importancia de la tenencia de la tierra dentro de la sociedad colombiana desde la época colonial. El jardín aparece como una metáfora del apego de esta sociedad a la tierra y como un síntoma de la relación entre lo agrario y lo político.

El jardín aparece de diferentes formas en las novelas de González; en Primero estaba el mar, al llegar los protagonistas a la casa que habían comprado, encuentran en un potrero al lado izquierdo de la casa un enorme árbol que hace pensar a J. en: “el árbol del bien y del mal” (González, 1983, p. 24). La referencia al Génesis y a aquella especie que crece junto al árbol de la vida en el Jardín del Edén (Génesis 2:9) constituye una clara alusión a la voluntad fundacional de la pareja de viajeros, aunque finalmente aquel lugar se convierta para ellos en lo opuesto a un Paraíso terrenal. Todos los finqueros que pueblan sus novelas posteriores son aficionados a cultivar jardines y a poblar de ganado los potreros de sus propiedades. El más cercano a nuestro protagonista es el personaje principal de Los caballitos del diablo (2003), desprovisto también de patronímico, nombrado a través de diferentes perífrasis como "aquel que se pierde entre árboles y jardines" (González, 2003, p. 46). En esta novela, el jardín sirve de refugio a las amenazas exteriores, el protagonista se aleja así de las tensiones familiares y de la violencia que empieza a generar el negocio del narcotráfico.

El origen rural de la población de Medellín y de sus alrededores los lleva a repetir en los jardines de sus casas el ambiente campestre de las fincas de sus antepasados. Inspirada en su propia historia familiar, Los caballitos del diablo describe la expansión urbanística de los años 1970 y la nostalgia por las antiguas casonas de los pueblos periféricos que terminaron devoradas por la expansión urbana. Narrando la relación de los personajes locales con su entorno, González se inscribe dentro de la tradición de la saga familiar propia de la narrativa antioqueña. En esta novela que González escribe a su regreso de una larga permanencia en los Estados Unidos, el protagonista trabaja de manera obsesiva en la construcción paisajística de su finca. Se trata de un espacio ordenado y fértil en el que se coleccionan especies vegetales y animales. La comparación bíblica vuelve a surgir de la boca de uno de sus hermanos, quien después de visitarla agrega que "todo le recordaba el Arca de Noé" (p. 105). El protagonista sabe que para 
lograr un jardín armonioso y colorido, el trabajo debe ser constante. Esta dedicación le permite mantener la mente alejada de los conflictos exteriores que representan el trabajo, la familia y los negocios. Para estos personajes la actividad paisajística se convierte en un tipo de terapia que va tomando importancia a medida que la violencia y los dramas familiares aumentan: "Su mujer lo vio llegar del Valle, del entierro de Emiliano y meterse día a día de madrugada entre los cafetales, a desyerbar, podar, deschamizar, y lo oyó vomitar; vio cómo se ponía más pálido, flaco y silencioso que nunca” (p. 112). El jardín parece aquí consolar mejor al doliente que su propia familia.

Si bien la misma búsqueda de evasión a través del trabajo campesino la encontramos en la última novela de González, las condiciones son diferentes, pues no se huye como en Los caballitos del diablo de los peligros exteriores, sino de aquellos más complejos que consisten en disipar las dudas existenciales. A pesar de su origen citadino, los personajes de González continúan profundamente ligados al campo, como la mayoría de la población colombiana de su generación. Una preocupación constante de este tipo de personajes es su interés por la posesión y acumulación de bienes raíces en forma de lotes, terrenos, fincas o haciendas. Muchos de los problemas que enfrentan son justamente generados por la venta, ocupación o herencia de tales bienes. Podemos citar al colono que se llenó de hectáreas en Primero estaba el mar, al finquero secuestrado en Abrabán entre bandidos o a los predios que El Rey de HonkaMonka consigue con la misma facilidad con que los pierde. Vemos que la tenencia de la tierra continúa siendo el ojo de huracán de la sociedad colombiana a pesar de haber pasado a ser mayoritariamente urbana.

La deambulación personal del escritor y las geografías que así ha descubierto marcan su narrativa. La vida familiar en Envigado aparece en La historia de Horacio. La finca donde la familia pasaba vacaciones en el Urabá antioqueño inspira obras como Primero estaba el mar, Manglares o Temporal, al igual que relatos recopilados en El lejano amor de los extraños o El Expreso del sol. Sus casi dos décadas de vida en los Estados Unidos se reflejan también en relatos del Rey de Honka-Monka, El Expreso del Sol y La Luz difícil; su regreso a Colombia y su instalación en las tierras frías de Cachipay, en Niebla al mediodía. Su última novela parece inspirarse en su reciente regreso a la tierra antioqueña de sus ancestros, aunque busque ponerle ciertas trampas al lector en el momento de localizar la acción. 
Son muchos los elementos que hacen que la última novela de González difiera de las anteriores. Lo primero que sorprende es el cambio de voz narrativa, el tradicional narrador en tercera persona se diluye dándole espacio a otras posibilidades narrativas. Además, el carácter autorreferencial de la primera persona hace que se instale un tono confesional y testamentario, que es nuevo en la obra del novelista antioqueño.

Como el propio autor que se acerca a los setenta años, el alter ego del narrador contempla los cambios físicos y mentales propios de la edad, y trata de adaptar el espacio a sus nuevas preocupaciones de hombre mayor. Es verdad que como en otras de sus novelas, Las noches todas comienza con un proyecto de cambio espacial:

Visité una tarde a mi hermana mayor y le anuncié que había decidido disminuir al máximo mis relaciones con los demás seres humanos. Pensaba vender el apartamento y comprar una casa con un buen terreno para dedicarme a la jardinería y a vivir en silencio con la tierra y las matas el resto de mis días (González, 20I8, p. 9).

La diferencia con otros desplazamientos es que esta vez parece tratarse de un cambio espacial definitivo, por una parte, por su edad y, por otra, por su voluntad de aislarse de los demás. Dos aspectos esenciales en toda la obra de González se destacan en este íncipit y dan las claves emocionales de la novela: la soledad y el silencio.

Los artistas que pueblan las novelas de González son por lo general seres tortuosos que buscan en el silencio un refugio a sus preocupaciones filosóficas. Para Maurice Blanchot (1943) la soledad del artista es el espacio ideal donde puede ejercer su creatividad, y el protagonista de Las noches todas parece buscar en la soledad del campo y en particular del jardín un lugar de inspiración y de sosiego que hasta entonces no ha alcanzado. Dentro de la tradición literaria el jardín, además de ser una materialización de la búsqueda de absoluto, constituye un espacio privilegiado para el arte, la imaginación y la poesía. El jardín que empieza a construir Esteban Latorre se convierte simbólicamente en la obra (poética) que no ha logrado materializar.

El segundo cambio importante con relación a sus novelas anteriores es el sentido epilogal de Las noches todas. Una sensación de fin de ciclo y de búsqueda de un espacio definitivo recorre todo el relato. Otras obras de González han tratado ya el tema de la muerte, especialmente La luz difícil, que toca el delicado tema de la eutanasia; o 
"Verdor", que inicia con el duelo de una pareja tras la muerte de su hijo, sin olvidar el asesinato del hermano que aparece en varios de sus relatos, principalmente en su opera prima. De la misma forma que el viaje, la muerte aparece en la obra de González como un desencadenante del relato; varios de ellos abren justamente con un evento dramático; citemos por ejemplo "Verdor", cuento que abre El rey del Honka-Monka:

Después de la tragedia se quedaron todavía por un tiempo en Bogotá. Pasadas las molestias del entierro, las palmadas en el hombro [...] él perdió la fortaleza que se le había visto después de la noticia (González, 1993, p. 13).

El drama surge con frecuencia en un contexto familiar; el más claro ejemplo es la muerte de J. en Primero estaba el mar, tema que retoma en Mar sin orillas, desde una perspectiva diferente. Esta tragedia, que enluta su propia historia, da comienzo a los hechos narrados en sus obras. Es el caso del cuento "Flotar", que abre El Expreso del Sol así: "Mi tía Angélica, la menor de mis tías maternas desapareció de nuestras vidas y de la vida de la familia cuando mi hermana gemela y yo teníamos trece años" (González, 2016, p. 11). "Miel", uno de los cuentos de El lejano amor de los extraños, abre así: "Néstor encendió la televisión en el momento en que dos soldados sacaban un cadáver carbonizado del edificio" (González, 2012, p. 99). Inicio parecido en otro cuento de este compendio titulado "Flores guardadas": "Luego de la muerte de Iván, el apartamento permaneció cerrado casi dos meses”(p. 157). El insomnio que abre $\mathrm{La}$ luz difícil anuncia también la tragedia familiar de la pareja protagonista: "Esa noche pasé mucho tiempo despierto. A mi lado, Sara tampoco dormía” (González, 2011, p. $11)$.

El espectro de la muerte recorre insistentemente la última novela de González. Desde su inicio el protagonista se ve asediado de ideas negativas, y la vejez aparece como el preámbulo del fin de vida. Esto se confirma ya en el título; por una parte, la oscuridad de "las noches" (perdón por la redundancia), acompañada del adjetivo "todas" que alude a una amplitud temporal indefinida. El novelista retoma la frase que cierra la novela, hecho también significativo, para titular su obra, en un párrafo que hace clara alusión a la muerte: 
Y muy de vez en cuando, pero con especial cercanía e intensidad, alcanzo a sentir también la oscuridad de estas mis últimas largas noches de insomnio y, con la de ellas, la oscuridad de los inicios, que es adonde iré a parar yo y adonde han ido a parar las noches todas (González, 2018, p. 210).

A pesar de esta tonalidad sombría que abre y cierra la novela, el espacio natural y, en nuestro caso particular, el jardín como reproducción artificial de una vegetación original y edénica vehiculan un sentimiento positivo y vital. El intelectual pensionado y depresivo encuentra en la concepción de este espacio idealizado la clave para no caer en el oscuro socavón de la muerte. Huir de la capital y de los cómodos cien metros cuadrados que habita parece ser el camino más sencillo para dejar atrás el espectro de la inactividad y el encierro. Al ser un espacio imaginado en el que se proyectan aspiraciones y sueños, el jardín se convierte en una utopía moderna donde el citadino deposita sus últimas ilusiones. En el paisaje hostil y contaminado de la urbe actual, el jardín se transforma en un espacio de ensoñación y de trascendencia.

El jardín exige múltiples habilidades. Además de su planeación y trazo, su práctica implica un trabajo manual cotidiano y un recurso constante a la creatividad. Una de las grandes ventajas de la horticultura es que ocupa a la vez el cuerpo y el espíritu, aspecto que el protagonista Esteban Latorre parece asimilar al decidir de entrada, en el primer párrafo de la novela, "comprar una casa con buen terreno para dedicarme a la jardinería y a vivir en silencio con la tierra y las matas el resto de mis días" (p. 9). A propósito, en su ensayo "La tierra y las ensoñaciones del reposo", Gaston Bachelard (1948) señala que el jardín, como la vida, es siempre un ejercicio inconcluso. Se trata en efecto de una práctica que por su constante transformación adquiere un sentido circular y que aspira así a la inmortalidad. Al ser un material vivo y en movimiento, el jardín constituye una labor en constante renovación y que nos hace olvidar el sentido perecedero de la vida.

En el libro ya citado, Bachelard (1948) analiza la simbología del rincón (le coin) como el espacio mismo del aislamiento (p. 137). Esta idea del jardín como rincón urbano o espacio extremo de lo personal y lo íntimo aparece también en la novela de González. $\mathrm{El}$ jardín se construye como un refugio espacial y mental; la búsqueda de la trascendencia espiritual se logra a través de la práctica del jardín que nos aleja de la divagación mental: 
[...] estábamos logrando crear un sitio en donde uno podía escapar de la ciudad misma, sin necesidad de salir, es decir, sin perderla. La comodidad es la incomodidad, como dicen los yoguis. Allí estaba mucho de su encanto. También nos elogió por haber acabado con los rincones desabridos. Eso era lo que él más temía, en materia de jardines y en todo lo demás de vida. Tampoco teníamos rincones tristes, aunque sí solitarios y melancólicos (González, 2018, p. 137).

En el caso particular de Las noches todas, el jardín le permite al protagonista alejarse de la inactividad inherente a la jubilación. Plantar, regar y podar se convierten en una forma de huir de la degradante realidad que constituye la vejez, edad que nos confronta irremediablemente con la proximidad de la muerte. Vladimir Jankélévitch (1963) reflexiona en su libro L'aventure, l'ennui, le serieux sobre la espera del último día y nuestra relación con la muerte. Según el filósofo francés, nuestro vínculo con el tiempo es particularmente ambivalente. La espera para Jankélévitch puede ser activa o pasiva, es decir una forma de agobiarse o por el contrario una manera de encontrarse uno mismo. La espera para el protagonista de nuestra novela es el resultado de un recorrido existencial, por eso trata de encontrar en el jardín y en todo aquello que rodea esta práctica una alternativa a la angustia del final. Para Jankélévitch existen varias formas de llenar ese vacío existencial; una puede ser el aburrimiento y otra puede ser el amor. A través de toda la novela nuestro personaje parece oscilar entre las dos.

El jardín ha tenido siempre una significación vital en los relatos de González; la contemplación y el trabajo en el campo son actividades mentalmente reconfortantes. Frente a la densidad demográfica los espacios verdes desaparecen y el jardín se convierte en un lugar deseado y accesible. Al no poder cambiar el mundo ni detener la degradación del medio ambiente, lo más accesible es crear su propio espacio y esculpirlo a su manera. El jardín refleja una marca individual de identidad y una expresión política.

Desde sus comienzos la obra de González ha tenido una clara inspiración ecológica. La pareja protagonista de su primera novela aspiraba a una sociedad justa y en armonía con la naturaleza, aunque termine devorada por la selva. Como en Primero estaba el mar, el protagonista de Las noches todas abandona el opresivo ambiente urbano para buscar en el campo el silencio y la paz interior. Han pasado más de cuatro décadas entre la publicación de las dos obras. El joven soñador de la 
primera se ha convertido en un jubilado apático que, anestesiado por la soledad y la inercia, decide arraigarse en el campo.

Después de su instalación y a medida que el jardín va tomando forma, Esteban se percata de su atracción por Aurora, su ayudante. Los sentimientos avanzan a la par de la materialización del espacio, y el jardín va pareciéndose cada vez más a ella: "Aurora se había convertido en parte del jardín, que empezaba a parecérsele. Para mi gusto los humanos alcanzan toda su belleza física por allá a los treinta y cinco, cuarenta años de edad" (González, 2018, p. 121). El jardín se consolida como el espacio soñado y Aurora como la mujer ideal. Debemos recordar que en la tradición literaria el jardín ha sido un lugar de sensualidad, ligado a lo femenino, a lo húmedo y a la fertilidad. En la literatura galante el jardín es lugar de encuentro sensual, y para los románticos constituye el lugar ideal de la ensoñación sentimental; nuestro mejor ejemplo es la finca El Paraíso, espacio del amor ideal de Efraín y María.

Según el Corán, el paraíso es un jardín atravesado por un río (Cazanave, 2000, p. 331). El agua, símbolo mayor de la vida, atraviesa también la propiedad de nuestro personaje y se convierte en el origen de las tensiones y en la razón de un nuevo cambio en la vida del protagonista, un eterno nómada. En esta novela no solo se opone nomadismo y sedentarismo; a sus protagonistas todo los separa: Esteban es introvertido y púdico, Aurora es dinámica y alegre. Él es viejo, ella es joven; él es académico, ella autodidacta; él es citadino, ella del campo. Lo que termina finalmente uniéndolos es su pasión por el jardín. La transparencia del nombre de la protagonista parece sintetizar la idea que el profesor se hace del jardín ideal, a la vez por su pureza, su luz y su musicalidad. El lugar de encuentro entre Aurora y Esteban es además el jardín, espacio que simboliza el fluir del tiempo.

El interés por la geografía y su repercusión en las diferentes etapas de la vida de los personajes es constante en las ficciones de Tomás González. Sus protagonistas aparecen al acecho de viajes y expediciones en espacios abiertos que cambian la monotonía y la frustración que la vida les depara. El mar, el bosque, la montaña aparecen de forma diversa en sus relatos, pero siempre como respuesta a una preocupación ontológica, a una búsqueda personal que exige una transformación interior, por lo general acompañada de un cambio geográfico. 
Los espacios exteriores de sus obras pasadas reflejan estados de ánimo convulsos. La escritura de González parece experimentar una evolución geográfica; los grandes espacios rurales o urbanos de sus primeras novelas van siendo remplazados por espacios más reducidos hasta llegar al espacio íntimo del jardín. En Las noches todas vemos que el desplazamiento espacial se transforma poco a poco en la estabilidad física y mental que se sintetiza en el jardín. Regresar al jardín que recuerda la casa paterna significa el retorno natural al lugar de origen que será el espacio definitivo del sosiego y de la trascendencia.

\section{Referencias bibliográficas}

Bachelard, G. (1948). La terre et les reveries du repos. Paris : Librairie José Conti.

Bachelard, G. (2006). La tierra y las ensoñaciones del reposo. Ensayo sobre las imágenes de la intimidad. México: Fondo de Cultura Económica.

Blanchot. M. (1943). L'espace littéraire. Paris : Gallimard.

Cazenave, M. (2000). Encyclopédie des symboles. Paris : Le Livre de Poche.

González, T. (1983). Primero estaba el mar. Bogotá: Los Papeles del Goce.

González, T. (1993). El rey del Honka-Monka. México: Grupo Editorial Planeta.

González, T. (2003). Los caballitos del diablo. Bogotá: Editorial Norma.

González, T. (2011). La luz dificil. Bogotá: Editorial Alfaguara.

González, T. (2012). El lejano amor de los extraños. Bogotá: Editorial Alfaguara.

González, T. (2016). El expreso del sol. Bogotá: Editorial Planeta.

González, T. (2018). Las noches todas. Bogotá: Editorial Planeta.

Jankélévitch, V. (1963). L'aventure, lennui, le serieux, Paris : Essais Flammarion. 